\title{
Mechanisms of human amniotic epithelial cell transplantation in treating stage III pressure ulcer in a rat model
}

\author{
AITING ZHOU ${ }^{1}$, XILAN ZHENG ${ }^{1}$, LIMEI YU $^{2}$, MINGTAO QUAN $^{3}$, XING SHAO $^{1}$ and ZHIXIA JIANG ${ }^{1}$ \\ ${ }^{1}$ College of Nursing, Zunyi Medical College; ${ }^{2}$ Cell Engineering Laboratory; ${ }^{3}$ Intensive Care Unit, \\ Affiliated Hospital of Zunyi Medical College, Zunyi, Guizhou 563000, P.R. China
}

Received November 26, 2014; Accepted July 9, 2015

DOI: $10.3892 /$ etm.2015.2778

\begin{abstract}
The aim of the present study was to determine the function of human amniotic epithelial cell transplantation (hAECT) in promoting the healing of rats with stage III pressure ulcer (PU) and to initially investigate its possible mechanisms. A total of 96 Sprague Dawley rats were allocated at random into the model, hAECT, conventional treatment or control groups ( $n=24$ per group). In each group, 6 rats were observed to determine the wound-healing rate. The mRNA and protein expression levels of vascular endothelial growth factor (VEGF) and tumor necrosis factor (TNF)- $\alpha$ in the wound tissue and serum were detected using reverse transcription-quantitative polymerase chain reaction analysis and enzyme-linked immunosorbent assay. The transplantation of hAECs significantly increased the healing rate of the stage III PUs and was accompanied by the significant upregulation of VEGF mRNA and protein expression levels and the significant downregulation of TNF- $\alpha$ mRNA and protein expression. Immunofluorescence staining showed that, on day 7 of transplantation, hAECs remained alive inside the skin tissues. Therefore, hAECT through subcutaneous injection appears to significantly improve the wound-healing rate of stage III PUs in rats, and this effect may be associated with the upregulation of the proangiogenic factor VEGF and the downregulation of the inflammatory cytokine TNF- $\alpha$.
\end{abstract}

\section{Introduction}

Local body tissues subjected to long-term pressure receive restricted blood flow and exhibit nutrient deficiency and the loss of normal functions, which may lead to tissue ulceration and necrosis, i.e. pressure ulcers (PUs) $(1,2)$. PUs are a commonly observed complication in long-term bedridden

Correspondence to: Dr Zhixia Jiang, College of Nursing, Zunyi Medical College, 201 Dalian Road, Zunyi, Guizhou 563000, P.R. China

E-mail: zhixiajiangcn@163.com

Key words: human amniotic epithelial cells, pressure ulcer, vascular endothelial growth factor, tumor necrosis factor- $\alpha$ patients suffering from a range of diseases, including coma, quadriplegia, senility and weakness, traumatic fixation and severe malnutrition $(3,4)$. A number of methods have been used to promote wound healing in PUs, with the primary method being the local application of drugs. Drugs based on Traditional Chinese Medicine, Western medicine and a combination of Chinese and Western medicine have been employed for the treatment of PUs $(5,6)$. Recently, with the development of stem cell technology, treatments aimed at various refractory diseases have additionally been developed (7-9). Human amniotic epithelial cells (hAECs) express embryonic stem cell markers, such as stage-specific embryonic antigen 3 (SSEA-3), SSEA-4, TRA-1-81, fibroblast growth factor 4 and Rex1d, in addition to pluripotent cell transcription factors, such as octamer-binding transcription factor 4 (Oct-4) and Nanog. hAECs may be induced to differentiate into cells of the three germinal layers in vivo and in vitro, and thus may be used as an experimental substitute for embryonic stem cells (10-12). In the present study, Sprague Dawley rats were used to establish a model to observe the effects of hAECT in treating stage III PU. Wound tissue samples were extracted at different time-points to detect the anti-inflammatory and tissue growth-promoting effects of the cells and to determine the expression of vascular growth-related factors. The aim of the study was to analyze the possible mechanisms underlying the effects of hAECs and to provide a basis for future preclinical studies using hAECs to treat stage III refractory PU.

\section{Materials and methods}

Acquisition of human amnion. hAECs for transplantation into rats were obtained from the placenta of parturient women recruited from the Department of Obstetrics of the Affiliated Hospital of Zunyi Medical College (Zunyi, China). Informed consent was obtained from all patients. The amniotic membrane was peeled from the fresh placenta of each parturient patient that underwent a full-term $\mathrm{C}$-section. Patients were excluded if they exhibited such diseases as hepatitis B, hepatitis C, syphilis and HIV.

Culture and identification. The amniotic membrane was peeled from the fresh placenta under aseptic conditions. After being washed with freshly prepared D-Hank's solution (Sigma-Aldrich, St. Louis, MO, USA), the amniotic 
Table I. Primer sequences.

\begin{tabular}{lcll}
\hline Gene & GenBank accession no. & \multicolumn{1}{c}{ Forward (5'-3') } & \multicolumn{1}{c}{ Reverse (5'-3') } \\
\hline TNF- $\alpha$ & NM_012675.3 & TCAGTTCCATGGCCCAGAC & GTTGTCTTTGAGATCCATGCCATT \\
VEGF & NM_031836.2 & GCACGTTGGCTCACTTCCAG & TGGTCGGAACCAGAATCTTTATCTC \\
$\beta$-actin & NM_031144.2 & GGAGATTACTGCCCTGGCTCCTA & GACTCATCGTACTCCTGCTTGCTG
\end{tabular}

TNF- $\alpha$, tumor necrosis factor- $\alpha$; VEGF, vascular endothelial growth factor.

membrane was cut into $2 \times 2-\mathrm{cm}$ pieces and digested in $0.02 \%$ EDTA-containing $0.05 \%$ trypsin solution (Fuzhou Maixin Biotechnology Development, Co., Ltd., Fuzhou, China), and $10 \%$ fetal bovine serum (FBS) (Fuzhou Maixin Biotechnology Development, Co., Ltd.) was used to terminate the digestion. The cell precipitate, comprising the primary hAECs, was resuspended in low-glucose Dulbecco's modified Eagle's medium containing $1 \% \beta$-mercaptoethanol, $1 \%$ GlutaMAX $^{\mathrm{TM}}$, $10 \% \mathrm{FBS}, 10 \mathrm{ng} / \mathrm{ml}$ epidermal growth factor and $1 \%$ non-essential amino acid (all reagents supplied by Hyclone Laboratories, Inc., Logan, UT, USA). The separated primary cells were seeded into a $25-\mathrm{cm}^{2}$ culture flask at a density of $5 \times 10^{5}$ cells $/ \mathrm{ml}$. After $72-96 \mathrm{~h}$, when the cell confluence was $>80 \%, 0.125 \%$ trypsin and $0.02 \%$ EDTA solution was used for the digestion, subculture and identification.

Flow cytometric analysis and immunocytochemical staining were performed to identify the hAECs. The 3-4 generations of hAMSCs were collected, and the cell density was adjusted to $2 \times 10^{5}$ cells $/ \mathrm{ml}$. Then, $200 \mu \mathrm{l}$ cell suspension was taken, and $10 \mu 1$ monoclonal CD44-PE (cat. no. 550989), CD90-FITC (cat. no. 555595), CD105-PerCP-Cv5.5 (cat. no. 560839), CD73-APC (cat. no. 560847), CD34-PE (cat. no. 555822), CD45-PE (cat. no. 555483), CD11b-PE (cat. no. 555388), CD19-PE (cat. no. 55413) and CDDR-PE (cat. no. 559868) antibodies (Shanghai Sangon Biological Engineering Technology and Services Co., Ltd., Shanghai, China) were added, respectively, followed by incubation at room temperature for $25 \mathrm{~min}$. Next, $2 \mathrm{ml}$ phosphate-buffered saline (PBS) containing $1 \mathrm{~g} / \mathrm{l} \mathrm{NaN}$ (Sigma-Aldrich) was added to each tube. After mixing, the mixture was centrifuge at $168 \mathrm{x} \mathrm{g}$ for $5 \mathrm{~min}$ and the supernatant was discarded. Following a further oscillation, the cells were suspended in PBS. Subsequently, $200 \mu 14 \%$ paraformaldehyde (Sigma-Aldrich) was added to each tube. The mixture was detected using a FACSCanto II flow cytometry cell analyzer (BD Biosciences, Franklin Lakes, NJ, USA), and the data were analyzed using Cell Quest software (BD Biosciences).

Preparation of animal model and grouping. A total of 96 adult male Sprague Dawley rats, weighing 120-150 g, were purchased from Chongqing Tengxin Bill Experimental Animals Sales Co., Ltd. [license no. SCXK (Yu) 2012-0005; Chongqing, China]. Model preparation was performed in accordance with the method in China patent no. ZL201420090436X (13). The rats were separated into the model, conventional treatment, hAECT and control groups ( $n=24$ per group). In the model group, each rat was fitted with a medical sterile applicator (Shanghai Precision Scientific Instruments Co., Ltd.,
Shanghai, China) to protect the wound following surgery, which was changed daily. In the conventional treatment group, the wounds were disinfected with $0.5 \%$ povidone-iodine and then exposed to infrared light for 15-20 min, once per day, and covered with $0.5 \%$ povidone-iodine solution, with the gauze saturated with solution but not dripping. A medical sterile applicator was used to fix the iodine gauze after the disinfection. Each of the steps, including disinfection, infrared-light irradiation and povidone-iodine gauze redressing, was performed daily under sterile conditions. In the hAECT group, each rat was immediately subcutaneously injected with hAEC (passage 4/5) single-cell suspension. The cell density was adjusted to $1 \times 10^{6} / \mathrm{ml}$ with D-PBS. The wound was divided into 8 parts, and 8 points were selected from the center and edges of the wound; $0.03 \mathrm{ml}$ cell suspension was injected into each transplantation point. In the normal control group, the rats had their leg hair shaved and were fixed on the operating table under anesthetic (1/100 g Propofol; Sigma-Aldrich), in a similar manner to the rats in the other groups, but did not undergo modeling or treatment. This study was conducted with approval from the Animal Ethics Committee of Zunyi Medical College (Zunyi, China).

Determination of survival status of hAECs. The survival status of hAECs in rat skin tissue was determined using an immunofluorescence staining method. The tissue sections were washed with PBS three times, for $5 \mathrm{~min}$ per time. Then the specimens were treated with $0.3 \%$ Triton-X100 (Sigma-Aldrich) for $15 \mathrm{~min}$, followed by blocking using $10 \%$ normal goat serum (Fuzhou Maixin Biotechnology Development Co., Ltd.) for $30 \mathrm{~min}$. A primary monoclonal mouse anti-human nucleus-specific antigen antibody (1:100; WBB1281; Wuhan Boster Biological Technology, Ltd., Wuhan, China) was added, followed by incubation at $4^{\circ} \mathrm{C}$ overnight. PBS substituting primary antibody was used as a control. After PBS washing, phycoerythrin (PE)-labeled secondary goat anti-mouse IgG antibody (1:500; sc-2031; Santa Cruz Biotechnology, Inc., La Jolla, CA, USA) was added, followed by incubation at $37^{\circ} \mathrm{C}$ for $1 \mathrm{~h}$. Sections were stained using 4',6-diamidino-2-phenylindole (DAPI; Sigma-Aldrich), followed by observation under a BX61 fluorescent microscope (Olympus Corporation, Tokyo, Japan) to obtain images. The red fluorescence (PE staining) was presented in human nuclei, and the blue fluorescence (DAPI staining) was presented in all nuclei.

General observation of $P U$ wound-healing rate. Sterile, transparent graph paper was used to draw the wound shape, in order to calculate the wound area and the wound-healing rate. The 
Table II. Would-healing rate changes following hAECT.

\begin{tabular}{lccc}
\hline Group & Day 1 $(\%)$ & Day 3 $(\%)$ & Day $7(\%)$ \\
\hline Model & $9.67 \pm 1.11$ & $14.83 \pm 1.47$ & $70.29 \pm 2.54$ \\
Conventional treatment & $10.17 \pm 1.17^{\mathrm{a}}$ & $16.33 \pm 1.11$ & $71.71 \pm 3.45^{\mathrm{a}}$ \\
hAECT & $12.33 \pm 1.97^{\mathrm{a}, \mathrm{b}}$ & $47.67 \pm 3.14^{\mathrm{a}, \mathrm{b}}$ & $91.43 \pm 2.13^{\mathrm{a}, \mathrm{b}}$ \\
\hline
\end{tabular}

Data are expressed as the mean \pm standard deviation, $\mathrm{n}=6$. ${ }^{\mathrm{P}}<0.01 \mathrm{vs}$. model group; ${ }^{\mathrm{b}} \mathrm{P}<0.05 \mathrm{vs}$. conventional treatment group. $\mathrm{hAECT}$, human amniotic epithelial cell transplantation.

wound-healing rate was calculated as follows: Wound-healing rate $=($ Original wound area - area at detection $) /$ original wound area $x 100 \%$. A healing rate of $>95 \%$ was considered to indicate complete recovery.

Reverse transcription-quantitative polymerase chain reaction $(R T-q P C R)$. On days 1,3 and 7 post-transplantation, the animals were intraperitoneally anesthetized and 3-g PU tissue specimens were collected. The total RNA was extracted using TRIzol ${ }^{\mathrm{TM}}$ reagent (Invitrogen Life Technologies Inc., Carlsbad, CA, USA) according to manufacturer's instructions. RT-qPCR was performed using PrimeScript ${ }^{\mathrm{TM}}$ RT kits (Takara Biotechnology Co., Ltd., Dalian, China) according to the manufacturer's instructions. The reverse transcription reaction condition occurred at $37^{\circ} \mathrm{C}$ for $15 \mathrm{~min}$, followed by $85^{\circ} \mathrm{C}$ for $5 \mathrm{sec}$, and the reaction system ( $20 \mu \mathrm{l}$ for each sample) was as follows: PrimeScript Buffer (5X), $4 \mu \mathrm{l}$; PrimeScript RT Enzyme Mix I, $1 \mu \mathrm{l}$; Oligo Dt Primer (50 $\mu \mathrm{mol} / \mathrm{l}), 1 \mu \mathrm{l}$; Random 6-mers (100 $\mu \mathrm{mol} / \mathrm{l}), 1 \mu \mathrm{l}$; and total RNA, $13 \mu \mathrm{l}$. The PCR system (15 $\mu$ l for each sample) was as follows: Premix Ex Taq (2X), $7.5 \mu \mathrm{l}$; forward primer $(10 \mu \mathrm{mol} / \mathrm{l}), 0.25 \mu \mathrm{l}$; reverse primer $(10 \mu \mathrm{mol} / \mathrm{l}), 0.25 \mu \mathrm{l}$; cDNA $(5 \mathrm{ng} / \mu \mathrm{l}), 3 \mu \mathrm{l}$; and $\mathrm{dH}_{2} \mathrm{O}$, $4 \mu \mathrm{l}$. Primers were designed and synthesized by Shanghai Invitrogen Biotechnology Co., Ltd. (Shanghai, China) (Table I). After an initial denaturation step of $15 \mathrm{~min}$ at $95^{\circ} \mathrm{C}$, the PCR cycling conditions were as follows: for TNF- $\alpha, 50$ cycles of $95^{\circ} \mathrm{C}$ for $15 \mathrm{sec}, 61^{\circ} \mathrm{C}$ for $15 \mathrm{sec}$, and $72^{\circ} \mathrm{C}$ for $15 \mathrm{sec}$; for VEGF, 40 cycles of $95^{\circ} \mathrm{C}$ for $10 \mathrm{sec}, 58^{\circ} \mathrm{C}$ for $15 \mathrm{sec}$, and $72^{\circ} \mathrm{C}$ for $10 \mathrm{sec}$. The relative expression level was determined using the $2^{-\Delta \Delta \mathrm{Ct}}$ analysis method (14).

Enzyme-linked immunosorbent assay (ELISA). On days 1, 3 and 7 post-transplantation, the animals were intraperitoneally anesthetized and whole blood samples were extracted from the abdominal aorta. The samples were left at room temperature for $1.5-2 \mathrm{~h}$ and then centrifuged at $1,509 \mathrm{x} \mathrm{g}$ at $-4^{\circ} \mathrm{C}$ for $20 \mathrm{~min}$. Serum was isolated for the ELISA and the optical density was measured at $450 \mathrm{~nm}$. Serum levels of vascular endothelial growth factor (VEGF) and tumor necrosis factor- $\alpha$ (TNF- $\alpha$ ) were calculated according to the linear regression equation of standard curves.

Statistical analysis. All statistical analysis was performed using SPSS software, version 17.0 (SPSS, Inc., Chicago, IL, USA). Data are presented as the mean \pm standard deviation. Comparisons between two groups were performed using the $\mathrm{t}$ test. $\mathrm{P}<0.05$ was considered to indicate a statistically significant difference.
Table III. Wound-healing time of each group.

\begin{tabular}{lc}
\hline Group & Healing time (days) \\
\hline Model & $9.83 \pm 0.69^{\mathrm{a}}$ \\
Conventional treatment & $9.17 \pm 0.69^{\mathrm{b}, \mathrm{c}}$ \\
hAECT & $5.5 \pm 1.52$ \\
\hline
\end{tabular}

Data are expressed as the mean \pm standard deviation, $n=6$. ${ }^{\mathrm{a}} \mathrm{P}<0.01$ and ${ }^{\mathrm{b}} \mathrm{P}<0.05$ vs. hAECT group; ${ }^{\mathrm{c}} \mathrm{P}<0.05$ vs. model group. hAECT, human amniotic epithelial cell transplantation.

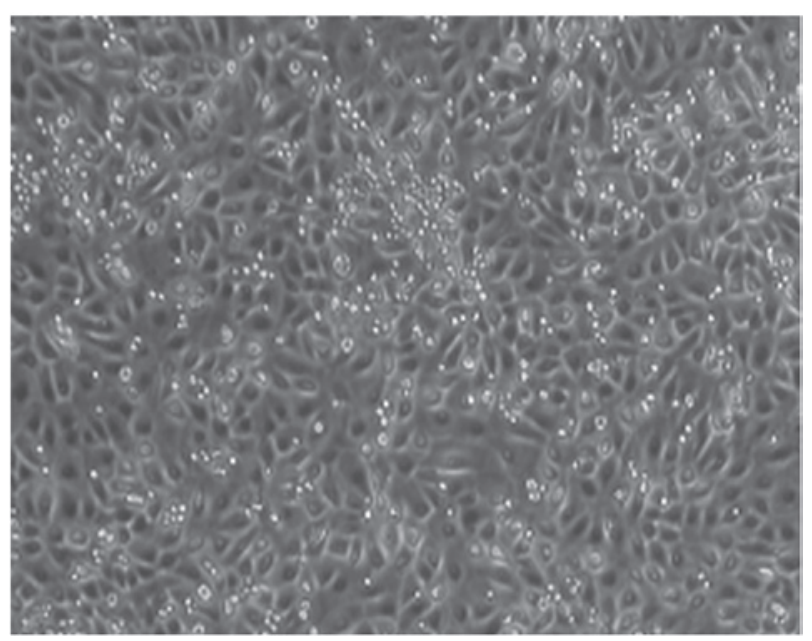

Figure 1. Culture morphology of human amniotic epithelial cells at passage 3 (magnification, x200).

\section{Results}

Morphology and phenotype identification. The confluence rate of third-generation hAECs cultured for 3-4 days was $\leq 80 \%$. Cell morphology was predominantly ovoid, with slabstone- and cobblestone-like growth patterns (Fig. 1).

Identification of hAECs by flow cytometry. Flow cytometric analysis and the immunocytochemical staining revealed that the isolated and cultured third-generation hAECs did not express cluster of differentiation (CD) 34, CD45, CD71, CD80 or CD86; however, the cells did express CD44, CD29, CD73 and CK19, which is consistent with the characteristic features of hAECs (Figs. 2 and 3). 

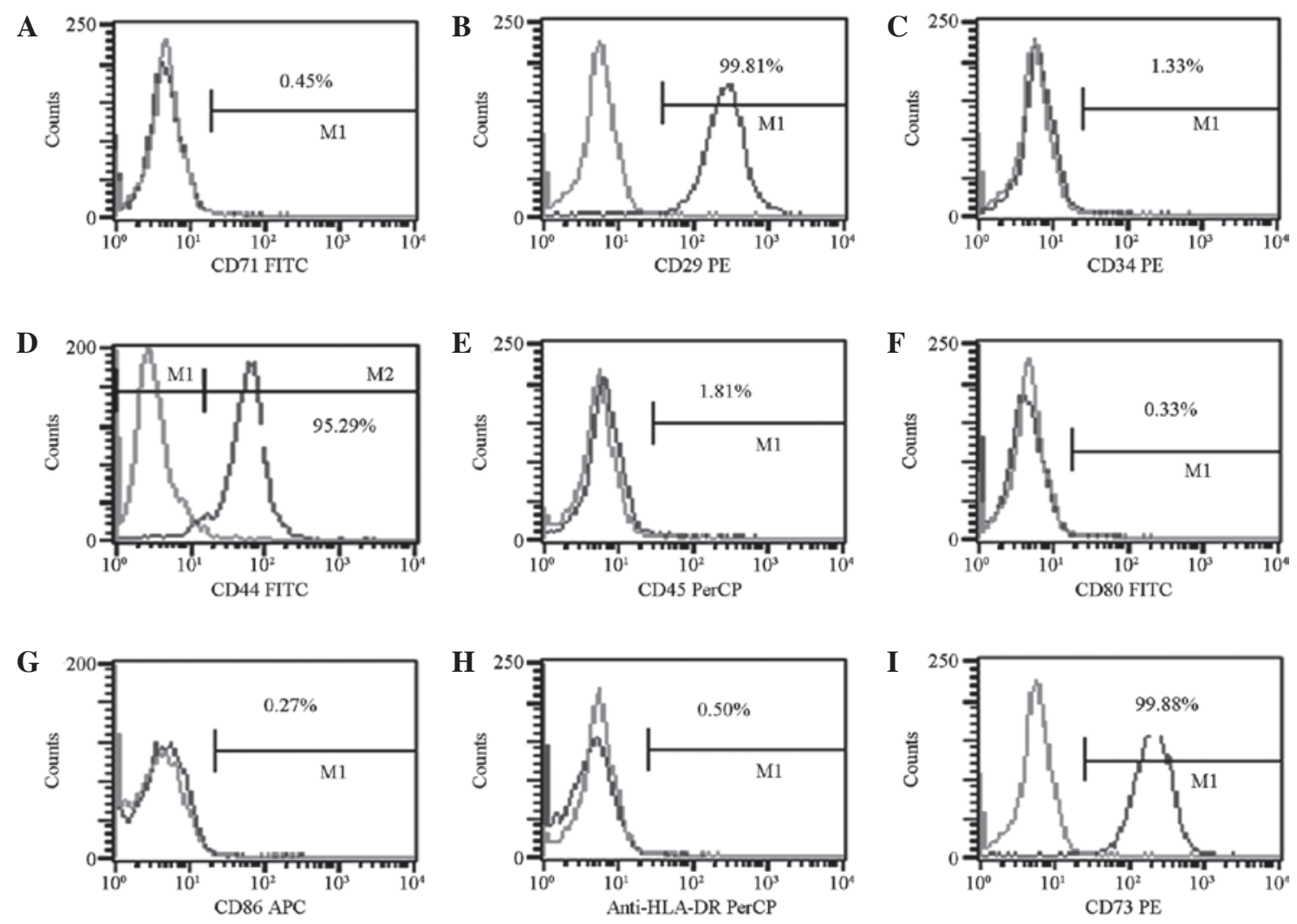

Figure 2. Phenotypic identification of human amniotic endothelial cells: (A) CD71, (B) CD29, (C) CD34, (D) CD44, (E) CD45, (F) CD80, (G) CD86, (H) anti-HLA-DR and (I) CD73. CD, cluster of differentiation; HLA-DR, anti-human leukocyte antigen-death receptor; FITC, fluorescein isothiocyanate; PE, phycoerythrin; APC, allophycocyanin.
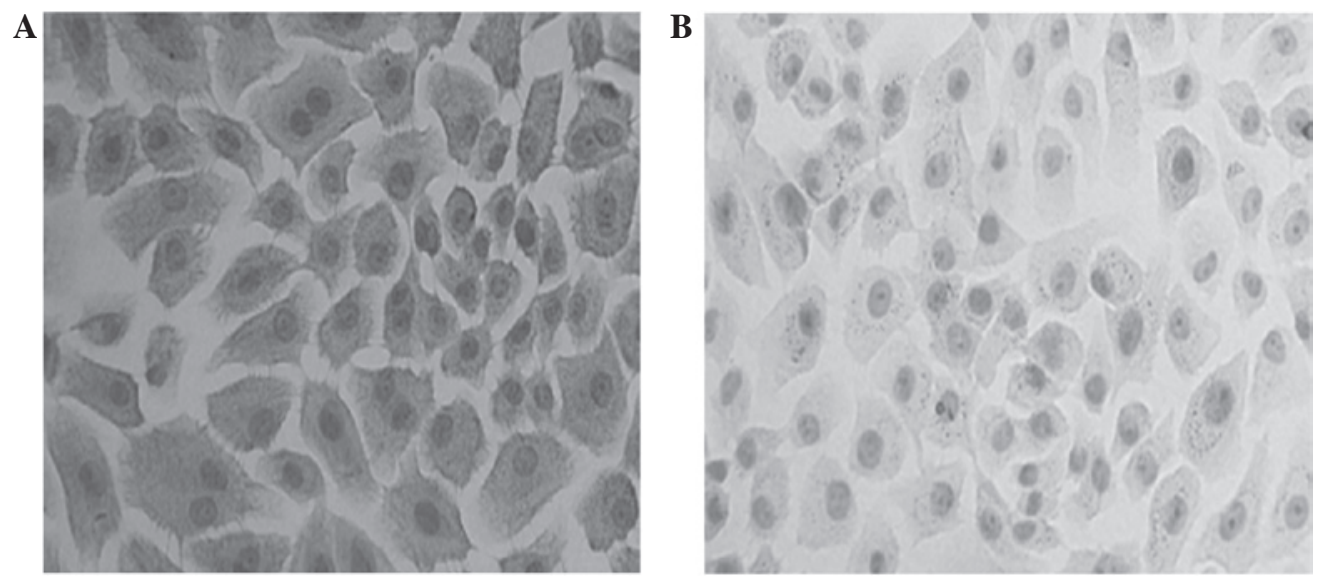

Figure 3. Expression of CK19 in hAECs. (A) CK19-positive hAECs and (B) negative control tissue (magnification, x400). hAEC, human amniotic epithelial cell; CK19, cytokeratin-19.

Survival status of hAECs. Immunofluorescence staining showed that, on post-transplantation day 7, the hAECT-group cells were positive for human nucleus-specific antigens under the transplantation subcutaneous region (MAB1281 positive, red fluorescence), indicating that on day 7 the hAECs remained alive in the rat skin tissues (Fig. 4).

Wound observation. On day 1 after the corresponding treatment in each group, the wound-healing rates of the conventional treatment and hAECT group were increased compared with the rate of the model group $(\mathrm{P}<0.05)$. At day 3 , the wound-healing rate of the hAECT group was significantly elevated compared with that of the model group and the conventional treatment group $(\mathrm{P}<0.05)$. On day 7 , the wound-healing rate of the hAECT group remained significantly elevated compared with that of the model and conventional treatment groups $(\mathrm{P}<0.05)$, and the wound-healing rate of the conventional treatment group was increased compared with that of the model group $(\mathrm{P}<0.05)$ (Table II).

Compared with the model and conventional treatment groups, the wound healing time of the hAECT group was significantly reduced $(\mathrm{P}<0.01$ and $\mathrm{P}<0.05$, respectively). The 
Table IV. Relative expression levels of VEGF mRNA in the pressure ulcer wound tissue of each group.

\begin{tabular}{lccr}
\hline Group & Day 1 & Day 3 & Day 7 \\
\hline Normal & $5.16 \pm 1.44$ & $5.13 \pm 1.76$ & $5.34 \pm 1.08$ \\
Model & $11.83 \pm 4.94^{\mathrm{a}}$ & $11.76 \pm 3.52^{\mathrm{a}}$ & $8.64 \pm 1.16^{\mathrm{a}, \mathrm{b}}$ \\
Conventional treatment & $12.97 \pm 5.78^{\mathrm{a}}$ & $11.66 \pm 2.76^{\mathrm{a}}$ & $10.00 \pm 1.29^{\mathrm{a}, \mathrm{c}}$ \\
hAECT & $24.88 \pm 7.39^{\mathrm{a}, \mathrm{b}, \mathrm{c}}$ & $24.33 \pm 6.58^{\mathrm{a}, \mathrm{b}, \mathrm{c}}$ & $15.63 \pm 3.46^{\mathrm{a}, \mathrm{b}, \mathrm{c}}$ \\
\hline
\end{tabular}

Data are expressed as the mean \pm standard deviation, $\mathrm{n}=6$. ${ }^{\mathrm{a}} \mathrm{P}<0.01$ vs. normal group; ${ }^{\mathrm{b}} \mathrm{P}<0.05$ vs. conventional treatment group; ${ }^{\mathrm{c}} \mathrm{P}<0.05$ vs. model group. VEGF, vascular endothelial growth factor; hAECT, human amniotic epithelial cell transplantation.

Table V. Comparison of serum VEGF levels in each group.

\begin{tabular}{llll}
\hline Group & Day 1 (ng/l) & Day 3 (ng/l) & Day 7 (ng/l) \\
\hline Normal & $12.18 \pm 1.07$ & $11.78 \pm 1.20$ & $12.24 \pm 1.35$ \\
Model & $14.46 \pm 1.16^{\mathrm{a}}$ & $22.50 \pm 2.96^{\mathrm{a}}$ & $17.35 \pm 1.60^{\mathrm{a}}$ \\
Conventional treatment & $14.54 \pm 0.53^{\mathrm{a}}$ & $22.37 \pm 2.26^{\mathrm{a}}$ & $16.49 \pm 1.63^{\mathrm{a}}$ \\
hAECT & $21.28 \pm 2.39^{\mathrm{a}, \mathrm{b}, \mathrm{c}}$ & $25.45 \pm 1.11^{\mathrm{a}, \mathrm{b}, \mathrm{c}}$ & $19.65 \pm 0.42^{\mathrm{a}, \mathrm{b}, \mathrm{c}}$ \\
\hline
\end{tabular}

Data are expressed as the mean \pm standard deviation, $\mathrm{n}=6$. ${ }^{\mathrm{a}} \mathrm{P}<0.01$ vs. normal group; ${ }^{\mathrm{b}} \mathrm{P}<0.05$ vs. conventional treatment group; ${ }^{\mathrm{C}}<0.05$ vs. model group. VEGF, vascular endothelial growth factor; hAECT, human amniotic epithelial cell transplantation.
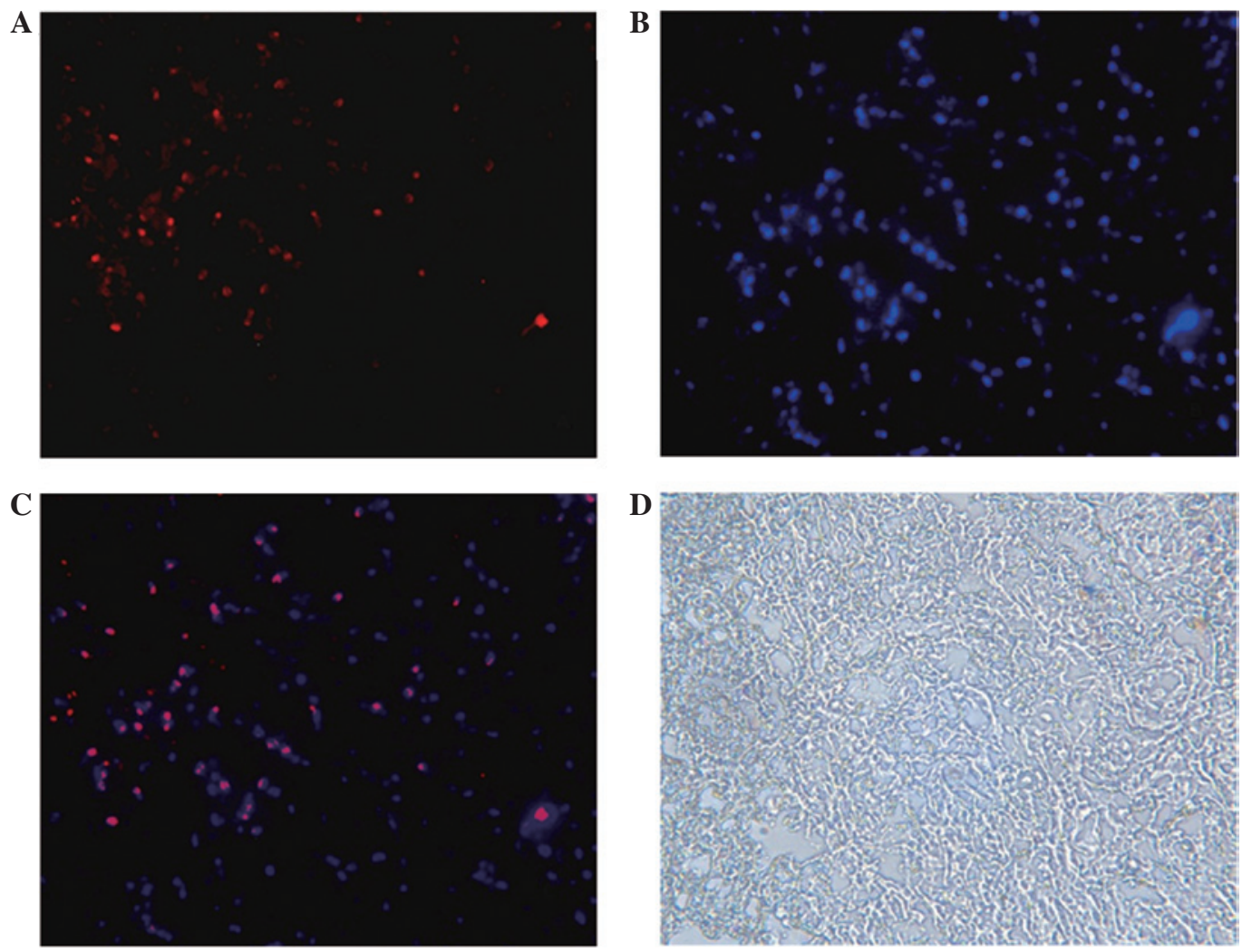

Figure 4. Detection of human nucleus-specific antigen. (A and B) Images of skin tissue under the same vision field (immunofluorescence; magnification, $\mathrm{x} 400$ ): (A) Human nucleus-specific antigen-positive cells (MAB1281, red fluorescence) and (B) following DAPI re-staining (blue fluorescence). (C) Combined image of A and B; (D) bright field-microscopy.

wound healing time of the conventional treatment group was significantly reduced compared with that of the model group $(\mathrm{P}<0.05)$ (Table III).
Expression of VEGF. On post-transplantation days 1, 3 and 7, the expression levels of VEGF mRNA and protein in the model, conventional treatment and hAECT groups were 
Table VI. Relative expression levels of TNF- $\alpha$ mRNA in the pressure ulcer wound tissue of each group.

\begin{tabular}{lccc}
\hline Group & Day 1 & Day 3 & Day 7 \\
\hline Normal & $2.12 \pm 0.53$ & $2.11 \pm 0.21$ & $2.19 \pm 0.37$ \\
Model & $3.97 \pm 0.95^{\mathrm{a}}$ & $3.24 \pm 0.26^{\mathrm{a}}$ & $3.02 \pm 0.15^{\mathrm{a}}$ \\
Conventional treatment & $3.97 \pm 0.68^{\mathrm{a}}$ & $3.41 \pm 0.36^{\mathrm{a}}$ & $3.09 \pm 0.12^{\mathrm{a}}$ \\
hAECT & $3.00 \pm 0.49^{\mathrm{a}}$ & $2.68 \pm 0.25^{\mathrm{a}, \mathrm{b}, \mathrm{c}}$ & $2.23 \pm 0.55^{\mathrm{a}, \mathrm{b}, \mathrm{c}}$ \\
\hline
\end{tabular}

Data are expressed as the mean \pm standard deviation, $\mathrm{n}=6$. ${ }^{\mathrm{a}} \mathrm{P}<0.01 \mathrm{vs}$. normal group; ${ }^{\mathrm{b}} \mathrm{P}<0.05 \mathrm{vs}$. conventional treatment group; ${ }^{\mathrm{c}} \mathrm{P}<0.05 \mathrm{vs}$. model group. TNF- $\alpha$; tumor necrosis factor- $\alpha$; hAECT, human amniotic epithelial cell transplantation.

Table VII. Comparison of serum TNF- $\alpha$ levels in each group.

\begin{tabular}{llll}
\hline Group & Day 1 (ng/l) & Day 3 (ng/l) & Day 7 (ng/l) \\
\hline Normal & $28.46 \pm 1.96$ & $28.94 \pm 1.98$ & $27.71 \pm 1.78$ \\
Model & $83.16 \pm 4.65^{\mathrm{a}}$ & $73.03 \pm 2.85^{\mathrm{a}}$ & $50.94 \pm 2.69^{\mathrm{a}}$ \\
Conventional treatment & $80.69 \pm 5.02^{\mathrm{a}}$ & $71.40 \pm 4.67^{\mathrm{a}}$ & $50.54 \pm 1.99^{\mathrm{a}}$ \\
hAECT & $75.58 \pm 3.75^{\mathrm{a}}$ & $51.40 \pm 2.44^{\mathrm{a}, \mathrm{b}, \mathrm{c}}$ & $31.85 \pm 2.75^{\mathrm{a}, \mathrm{b}, \mathrm{c}}$ \\
\hline
\end{tabular}

Data are expressed as the mean \pm standard deviation, $\mathrm{n}=6$. ${ }^{\mathrm{a}} \mathrm{P}<0.01 \mathrm{vs}$. normal group; ${ }^{\mathrm{b}} \mathrm{P}<0.05 \mathrm{vs}$. conventional treatment group; ${ }^{\mathrm{C}}<0.05$ vs. model group. TNF- $\alpha$; tumor necrosis factor- $\alpha$; hAECT, human amniotic epithelial cell transplantation.

increased compared with those in the normal control group $(\mathrm{P}<0.01)$. VEGF expression levels in the hAECT group were significantly elevated compared with those in the model and conventional treatment groups $(\mathrm{P}<0.05)$. On post-transplantation day 7, the expression levels of VEGF mRNA and protein in the conventional treatment group were higher compared with those in the model group $(\mathrm{P}<0.05)$ (Tables IV and $\mathrm{V})$.

Expression levels of TNF- $\alpha$. On post-transplantation days 1, 3 and 7, the expression levels of TNF- $\alpha$ mRNA and protein in the model and conventional treatment groups were significantly increased compared with those in the normal control group $(\mathrm{P}<0.01)$. On post-transplantation days 3 and 7 , the expression levels of TNF- $\alpha$ mRNA and protein in the hAECT group were significantly reduced compared with those in the model and conventional treatment groups $(\mathrm{P}<0.01)$ (Tables VI and VII).

\section{Discussion}

hAECs exhibit the property of 'immune privilege' and do not express the human leukocyte antigen-A, B, C and DR antigens. Grafted hAECs are also able to secrete immunosuppressive factors, such as TNF- $\alpha$, TNF-related apoptosis-inducing ligand and TGF- $\beta$, thus inhibiting the chemotactic activities of neutrophils and macrophages $(15,16)$. In addition, hAECs exhibit no telomerase activity, and thus may avoid the occurrence of post-transplantation teratoma. A previous study (17) reported that hAECs express the Oct- 4 and Nanog genes, which are key genes in embryonic stem cells for the maintenance of their differentiation abilities. To date, no studies have confirmed the expression of HLA-A, B, C and DR antigens in hAECs (18), indicating that hAECs experience no repellency and may avoid immune rejection following the transplantation (19). In addition, hAECs possess no telomerase and exhibit no tumorigenicity; therefore, from the view-point of biological safety, hAECs are ideal donor cells for the treatment of PU (20).

The results of RT-qPCR indicated that, on days 1,3 and 7 post-transplantation, the expression levels of VEGF mRNA in the wounds of the model and conventional treatment groups were increased compared with those in the normal control group, while the expression levels of the hAECT group were significantly higher than those of the model and conventional treatment groups. Furthermore, the ELISA results suggested that the serum VEGF level began to increase on day 1 after hAECT, and was significantly higher than that of the other groups by day 3. By day 7, the serum VEGF content in the hAECT group remained elevated compared with that in the other groups, while it was decreased compared with the levels detected on day 1. VEGF, also known as vascular permeability factor, is a glycoprotein originally isolated from an in vitro culture of bovine pituitary stellate cells (21). Numerous experiments $(22,23)$ have confirmed that VEGF performs two primary functions: i) VEGF specifically promotes the proliferation of endothelial cells and induces angiogenesis in vitro and in vivo, with experiments showing VEGF to be the strongest pro-vascular endothelial cell mitogen; ii) VEGF induces enhanced microvascular permeability, resulting in the widespread leakage of plasma proteins, including fibrinogen, plasminogen and fibronectin $(22,23)$. These proteins directly or indirectly alter the extracellular primary constituents, forming a temporary new matrix to support the migration of endothelial cells and fibroblasts, which promotes wound healing. In chronic wounds, as the expression levels of VEGF protein and mRNA are downregulated compared with those in normal wounds, the rate of angiogenesis declines, which is 
considered to inhibit chronic wound healing (24). The results of the present study demonstrated that the tissue and serum VEGF content was increased in the hAECT group, suggesting that hAECs stimulated the surrounding tissues to secrete VEGF, thus promoting the recovery of lesion areas.

The results of the RT-qPCR analysis demonstrated that, on post-transplantation days 1,3 and 7 , the TNF- $\alpha$ mRNA expression levels in the PU wound tissues of the model and conventional treatment groups were significantly elevated compared with those in the normal control group; on days 3 and 7, the TNF- $\alpha$ mRNA expression levels in the PU wound tissues of the hAECT group were significantly reduced compared with those in the model and conventional treatment groups, while the rat serum TNF- $\alpha$ level was increased compared with that of the normal group $(\mathrm{P}<0.05)$. On days 3 and 7 , the serum TNF- $\alpha$ content of the hAECT group was significantly reduced compared with that of the model and conventional treatment groups. TNF is an oligomer of glycoproteins; its receptor is widely distributed and numerous normal cells, including human vascular endothelial cells, fibroblasts, human embryonic lung cells and rat liver cells, are able to express TNF receptor (25). TNF can stimulate the generation, release and chemotactic response of polymorphonuclear (PMN) leukocytes in the peripheral blood, activating and generating a large quantity of toxic products that cause damage to tissues (26). TNF exerts direct toxic effects in endothelial cells, such as causing the cell surface to become procoagulant, thus promoting thrombosis, and inducing the secretion of neurotransmitters, resulting in the adhesion and activation of PMN leukocytes. TNF can also affect liver cells, inhibiting the generation of albumin and promoting the synthesis of certain acute-phase proteins (27). Two molecular forms of human TNF have been identified: TNF- $\alpha$ and TNF- $\beta(28,29)$. TNF- $\alpha$, also known as cachectin, is produced by bacterial lipopolysaccharide-activated monocytes and macrophages and can induce hemorrhage and necrosis in tumor tissues. TNF- $\beta$, also known as lymphotoxin, is produced by antigen- or mitogen-stimulated lymphocytes, exhibiting tumor-killing and immunoregulatory functions $(28,29)$; however, research has tended to focus on TNF- $\alpha$, which is a key inflammatory cytokine involved in the regulation of the immune and inflammatory responses. TNF- $\alpha$ serves an anti-infection function, in addition to promoting the healing of damaged tissues. Under certain conditions, TNF- $\alpha$ may be favorable to the body; however, the excessive generation of TNF- $\alpha$ or disordered interaction between TNF- $\alpha$ and other cytokines, may cause a series of inflammatory lesions (26).

The results of the present study suggested that the wound-healing rate of the hAECT group was increased compared with that of the model and conventional treatment groups, and the healing time was reduced compared with that of the model and conventional treatment groups. The expression levels of TNF- $\alpha$ in the hAECT group on post-transplantation days 1, 3 and 7 were significantly elevated compared with those in the normal control, model and conventional treatment groups, indicating that the hAECs were able to differentiate and promote wound healing in the ischemic and hypoxic PU wounds (30,31); however, the level of TNF- $\alpha$ at day 7 was reduced compared with that in the model and conventional treatment groups, which further indicated that, in the late period of wound healing, the overexpression of TNF- $\alpha$ may lead to its disordered interaction with other cytokines, resulting in increased inflammatory damage (20).

In conclusion, hAECs are able to secrete various growth factors, and hAECT, through subcutaneous injection, appears to significantly improve the wound-healing rate of stage III PUs in rats. Further studies may help to elucidate the biological mechanisms underlying the effects of hAECs in treating PU.

\section{Acknowledgements}

This study was funded by the Guizhou Provincial Science and Technology Fund Committee [no. Qiankehe J LKZ (2012) no. 23].

\section{References}

1. European Pressure Ulcer Advisory Panel (EPUAP) and National Pressure Ulcer Advisory Panel (NPUAP): Pressure Ulcer Treatment: Quick Reference Guide. http://www.epuap.org/guidelines/Final_Quick_Treatment.pdf.

2. Gould LJ, Olney CM, Nichols JS, Block AR, Simon RM and Guihan M: Spinal cord injury survey to determine pressure ulcer vulnerability in the outpatient population. Med Hypotheses 83: $552-558,2014$.

3. Lui TH: Technical tip: Percutaneous bone shaving and ulcer endoscopy to manage abnormal pressure point of the sole. Foot (Edinb) 24: 190-194, 2014.

4. Baharestani MM and Ratliff C: Pressure ulcers in neonates and children: An NPUAP white paper. Adv Skin Wound Care 20: 208, 210, 212, 214, 216, 218-220, 2007.

5. Barrufet MP, Vendrell E, Force L, Sauca G, Rodríguez S, Martínez E, Palomera E, Serra-Prat M, Capdevila JA, Cornudella J, et al: Prevalence and risk factors for meticillin-resistant Staphylococcus aureus in an acute care hospital and long-term care facilities located in the same geographic area. Rev Esp Quimioter 27: 190-195, 2014.

6. Wang LH, Chen HL, Yan HY, Gao JH, Wang F, Ming Y, Lu L and Ding JJ: Inter-rater reliability of three most commonly used pressure ulcer risk assessment scales in clinical practice. Int Wound J: Sep 16, 2014 (Epub ahead of print)

7. Lunn JS, Sakowski SA, Federici T, Glass JD, Boulis NM and Feldman EL: Stem cell technology for the study and treatment of motor neuron diseases. Regen Med 6: 201-213, 2011.

8. Lunn JS, Sakowski SA, Hur J and Feldman EL: Stem cell technology for neurodegenerative diseases. Ann Neurol 70: 353-361, 2011.

9. Nishimura K and Takahashi J: Therapeutic application of stem cell technology toward the treatment of Parkinson's disease. Biol Pharm Bull 36: 171-175, 2013.

10. Miki T, Lehmann T, Cai H, Stolz DB and Strom SC: Stem cell characteristics of amniotic epithelial cells. Stem Cells 23: 1549-1559, 2005.

11. Marcus AJ, Coyne TM, Rauch J, Woodbury D and Black IB: Isolation, characterization and differentiation of stem cells derived from the rat amniotic membrane. Differentiation 76: 130-144, 2008.

12. Ghionzoli M, Repele A, Sartiani L, Costanzi G, Parenti A, Spinelli V, David AL, Garriboli M, Totonelli G, Tian J, et al: Human amniotic fluid stem cell differentiation along smooth muscle lineage. FASEB J 27: 4853-4865, 2013.

13. Jiang ZX, Zhou AT, Zheng XL, et al: The animal model machine of pressure sores. China Patent ZL201420090436X, Filed July 16, 2014.

14. Livak KJ and Schmittgen TD: Analysis of relative gene expression data using real-time quantitative PCR and the 2(-Delta Delta C(T)) method. Methods 25: 402-408, 2001.

15. Wu CC, Wu TC, Liu FL, Sytwu HK and Chang DM: TNF- $\alpha$ inhibitor reverse the effects of human umbilical cord-derived stem cells on experimental arthritis by increasing immunosuppression. Cell Immunol 273: 30-40, 2012.

16. Manuelpillai U, Lourensz D, Vaghjiani V, Tchongue J, Lacey D, Tee JY, Murthi P, Chan J, Hodge A and Sievert W: Human amniotic epithelial cell transplantation induces markers of alternative macrophage activation and reduces established hepatic fibrosis. PLoS One 7: e38631, 2012. 
17. Wan P, Wang X, Ma P, Gao N, Ge J, Mou Y and Wang Z: Cell delivery with fixed amniotic membrane reconstructs corneal epithelium in rabbits with limbal stem cell deficiency. Invest Ophthalmol Vis Sci 52: 724-730, 2011.

18. Marcus AJ, Coyne TM, Black IB and Woodbury D: Fate of amnion-derived stem cells transplanted to the fetal rat brain: Migration, survival and differentiation. J Cell Mol Med 12: 1256-1264, 2008.

19. Le Blanc K, Tammik C, Rosendahl K, Zetterberg E and Ringdén O: HLA expression and immunologic properties of differentiated and undifferentiated mesenchymal stem cells. Exp Hematol 31: 890-896, 2003.

20. Javanmard SH, Hasanpour Z, Abbaspoor Z, Naderian GA and Jahanmard M: Aqueous concentrations of VEGF and soluble VEGF receptor-1 in diabetic retinopathy patients. J Res Med Sci 17: 1124-1127, 2012.

21. Neuss S, Becher E, Wöltje M, Tietze L and Jahnen-Dechent W: Functional expression of HGF and HGF receptor/c-met in adult human mesenchymal stem cells suggests a role in cell mobilization, tissue repair and wound healing. Stem Cells 22: 405-414, 2004.

22. Shizukuda Y, Tang S, Yokota R and Ware JA: Vascular endothelial growth factor-induced endothelial cell migration and proliferation depend on a nitric oxide-mediated decrease in protein kinase Cdelta activity. Circ Res 85: 247-256, 1999.

23. Murohara T, Horowitz JR, Silver M, Tsurumi Y, Chen D, Sullivan A and Isner JM: Vascular endothelial growth factor/vascular permeability factor enhances vascular permeability via nitric oxide and prostacyclin. Circulation 97: 99-107, 1998.

24. Miki T and Strom SC: Amnion-derived pluripotent/multipotent stem cells. Stem Cell Rev 2: 133-142, 2006.
25. Ma DH, Yao JY, Kuo MT, See LC, Lin KY, Chen SC, Chen JK, Chao AS, Wang SF and Lin KK: Generation of endostatin by matrix metalloproteinase and cathepsin from human limbocorneal epithelial cells cultivated on amniotic membrane. Invest Ophthalmol Vis Sci 48: 644-651, 2007.

26. Zhang S, He H, Day AJ and Tseng SC: Constitutive expression of inter- $\alpha$-inhibitor $(\mathrm{I} \alpha \mathrm{I})$ family proteins and tumor necrosis factor-stimulated gene-6 (TSG-6) by human amniotic membrane epithelial and stromal cells supporting formation of the heavy chain-hyaluronan (HC-HA) complex. J Biol Chem 287: 12433-12444, 2012.

27. Li H, Niederkorn JY, Neelam S, Mayhew E, Word RA, McCulley JP and Alizadeh $\mathrm{H}$ : Immunosuppressive factors secreted by human amniotic epithelial cells. Invest Ophthalmol Vis Sci 46: 900-907, 2005.

28. Chen X and Oppenheim JJ: Contrasting effects of TNF and anti-TNF on the activation of effector T cells and regulatory T cells in autoimmunity. FEBS Lett 585: 3611-3618, 2011.

29. Higashi N: Function, molecular structure and gene expression regulation of tumor necrosis factor and lymphotoxin. Nihon Rinsho 50: 1939-1944, 1992 (In Japanese).

30. Zani A, Cananzi M, Fascetti-Leon F, Lauriti G, Smith VV, Bollini S, Ghionzoli M, D'Arrigo A, Pozzobon M, Piccoli M, et al: Amniotic fluid stem cells improve survival and enhance repair of damaged intestine in necrotising enterocolitis via a COX-2 dependent mechanism. Gut 63: 300-309, 2014

31. Akrami H, Soheili ZS, Sadeghizadeh M, Khalooghi K, Ahmadieh H, Kanavi MR, Samiei S and Pakravesh J: Evaluation of RPE65, CRALBP, VEGF, CD68 and tyrosinase gene expression in human retinal pigment epithelial cells cultured on amniotic membrane. Biochem Genet 49: 313-322, 2011. 